\title{
Pesticides exposure and the use of personal protective equipment by cocoa farmers in Ghana
}

\author{
Elvis Dartey Okoffo ${ }^{1}$, Michael Mensah ${ }^{2}$ and Benedicta Yayra Fosu-Mensah ${ }^{*}$
}

\begin{abstract}
Background: The hazards of pesticide exposure have been a growing concern globally. The increase of susceptibility of farmers to pesticide intoxication is due to lack of knowledge regarding safe and proper pesticide handling. The aim of this study was to evaluate cocoa farmers' pesticide exposure by assessing the ways in which they store pesticides, operational habits exhibited during and after pesticide application and the use of personal protective equipment (PPE) during pesticide application in the Brong Ahafo Region of Ghana.
\end{abstract}

Methods: Two hundred and forty (240) cocoa farmers were randomly selected and interviewed using a structured questionnaire.

Results: Majority of the farmers were aware of the negative effects of pesticides on their health and the environment if not well handled. Despite the awareness, most farmers did not handle pesticides with care and do not adhere to the use of PPE, hence, increasing their risks to danger of exposure to pesticides. Storage of pesticides in bedrooms was reported by $22.5 \%$ of farmers; an indication of a high risk of pesticides exposure through direct inhalation. Cocoa farmers' in the study area exhibited operational habits such as eating, drinking water and alcohol, smoking cigarette and tobacco pipes, chewing gum and sticks, talking, using the mouth to remove blockages from sprayer nozzles, stirring pesticides with bare hands, among others during pesticides application. The survey revealed that only $35 \%$ of farmers put on full PPE while $45 \%$ put on partial PPE [which is any or combination of the following; cap/hat, respirator, goggle, rubber glove, overall and wellington boot (rubber boot)] during pesticides application. On the other hand, $20 \%$ of farmers in the study area applied pesticides without wearing PPE. These practices expose farmers to adverse health risks. Factors that influenced farmers' decision to use PPE included farming experience, age of farmer, access to extension service, availability of a chemical shop, farm size and educational level.

Conclusion: The results indicate high risks of exposure of cocoa farmers in the study area to toxicity and health hazards of pesticides due to mishandling and habits exhibited during pesticide application. There is a need to improve habits of safe use and handling of pesticides among farmers through education and training. There is also a need for education on the use of PPE during pesticides application to avoid exposure and health hazards.

Keywords: Exposure, Health risk, Pesticides, Protective equipment, Pollution

\section{Background}

Cocoa is a major agricultural export commodity and the main cash crop in Ghana. However, over the years cocoa production has faced major challenges, among these is

\footnotetext{
*Correspondence: yayramensah@staff.ug.edu.gh

1 Institute for Environment and Sanitation Studies (IESS), University of Ghana, P. O. Box 209, Legon, Accra, Ghana

Full list of author information is available at the end of the article
}

the incidence of insect pests and diseases which has been recognized as a major cause of declining yields in cocoa (Ayenor et al. 2007; Ntiamoah and Afrane 2008). This has adverse consequences for the country's economy. In recent years, there has been an increase in the use of pesticides in order to increase cocoa productivity. However, climate change with its associated impact on pests and diseases resistance to chemical control has led to 
increase in the intensity and frequency and sometimes the misuse of pesticides. The misuse of pesticides to control pests and diseases has major health related problems among smallholder farmers. This has become a global issue which has attracted attention of researchers, policy makers and the general public (consumers).

Globally there has been an increase in the incidence of pesticide poisoning with an estimated 1-41 million people suffering health effects from exposure to pesticides every year (PAN International 2007). According to the World Health Organization (WHO) (2009), a minimum of 300,000 people die from pesticides poisoning each year, with $99 \%$ of these from low- and middle-income countries. The exposure to pesticides are reported to have long term effects on thyroid function, cause low sperm count in males, birth defects, increase in testicular cancer, reproductive and immune malfunction/problems, endocrine disruptions, dermatitis, behavioural changes, cancers, immunotoxicity, neurobehavioral and developmental disorders (PAN International 2007; Mesnage et al. 2010; Tanner et al. 2011; Cocco et al. 2013; Gill and Garg 2014). Additionally, there are reports on the short term effects such as headaches, body aches, skin and eye irritation, respiratory problems, dizziness, impaired vision and nausea (Pan-Germany 2012; Gill and Garg 2014). The increase of susceptibility of farmers to pesticide related risks is due to lack of knowledge regarding safe and proper pesticide handling as well as disregard for the use of personal protective equipment (PPE) during pesticides use. Pesticides enter the human body mostly through inhalation and dermal absorption during application, but also, during pesticides preparation. To reduce the exposure to pesticides and health related risks, the use of PPE by farmers during pesticides application has been recommended by the International Labour Organization (ILO) and the World Health Organization (WHO) (International Labour Organization (ILO) (1991).

The Brong Ahafo region is one of the major cocoa producing regions in Ghana. Farmers in this region use pesticides extensively for the control of pests and diseases in order to increase cocoa yield. These chemicals however, are used improperly or in dangerous combinations with disregard for recommended safety measures hence exposing farmers to health risks. Unfortunately, there is little documented information on pesticides exposure, safety measures and operational habits of cocoa farmers during pesticides application in this region. The objective of this paper was to assess the exposure of cocoa farmers to pesticides, ways of storage of pesticides, the operational habits that leads to exposure and the pattern of use of PPE during pesticides application in the Brong Ahafo region of Ghana.

\section{Methods}

\section{Study area}

The study was carried out in the Dormaa West District which is located at the western part of the Brong Ahafo Region of Ghana with slightly hilly terrain (240-300 m above sea level). It shares boundaries in the north with the Dormaa Central Municipality, in the east with Asunafo North Municipality, in the west with Côte d'Ivoire and in the south by Bia East District (Fig. 1). Dormaa West District has a total population of 47,678 , made up of $48.2 \%$ females $(22,997)$ and $51.8 \%$ males $(24$, 681) (Ghana Statistical Service 2014). The highest mean temperature of the District is about $30{ }^{\circ} \mathrm{C}$ which occurs between March and April and the lowest is about $26.1{ }^{\circ} \mathrm{C}$ and occurs in August. It lies in the sub-humid zone (with annual total rainfall of $800-1200 \mathrm{~mm}$ ) and has a bimodal rainfall regime. The climatic condition of the study area is suitable for the cultivation of various cash crops such as cocoa and coffee, as well as food crops such as plantain, cocoyam and cassava. Farmers farm lands generally varied from small ( $0.5 \mathrm{ha})$ and spatially dispersed parcels to larger plots (10 ha) due to land fragmentation.

\section{Sampling technique and data collection}

The study was carried out from December 2014 to February 2015. The basic information for the analysis was obtained from primary data collected with the aid of a pre-tested semi-structured questionnaire. Three focus group discussions were also carried out to double check the individual responses. The multi-stage sampling technique was used to select the respondents for the study. Multi-stage sampling creates a more representative sample of the population than a single sampling technique and can help reduce costs of large-scale survey research (Green et al. 2006). It is often preferred for reasons of precision and economy. This sampling technique employs more than one stage and combines a number of sampling techniques. The specified number of stages depends on the study undertaken (Panneerselvam 2004). The multistage sampling in this study entailed four (4) stages. In the first stage, the Brong Ahafo Region of Ghana was purposively selected due to the high production of cocoa in the region. In the second stage, the Dormaa West District which is known to be one of the major cocoa growing areas in the Brong Ahafo region was randomly selected out of the several cocoa producing districts in the Region. In the third stage, four (4) major cocoa growing communities, namely, Nkrankwanta, Diabaa, Krakrom and Kwakuanya were randomly selected from a list of cocoa producing communities in the district. In the final stage, sixty (60) cocoa farmers were randomly selected from each of the four selected cocoa growing communities. A total of 240 cocoa farmers were randomly sampled for 


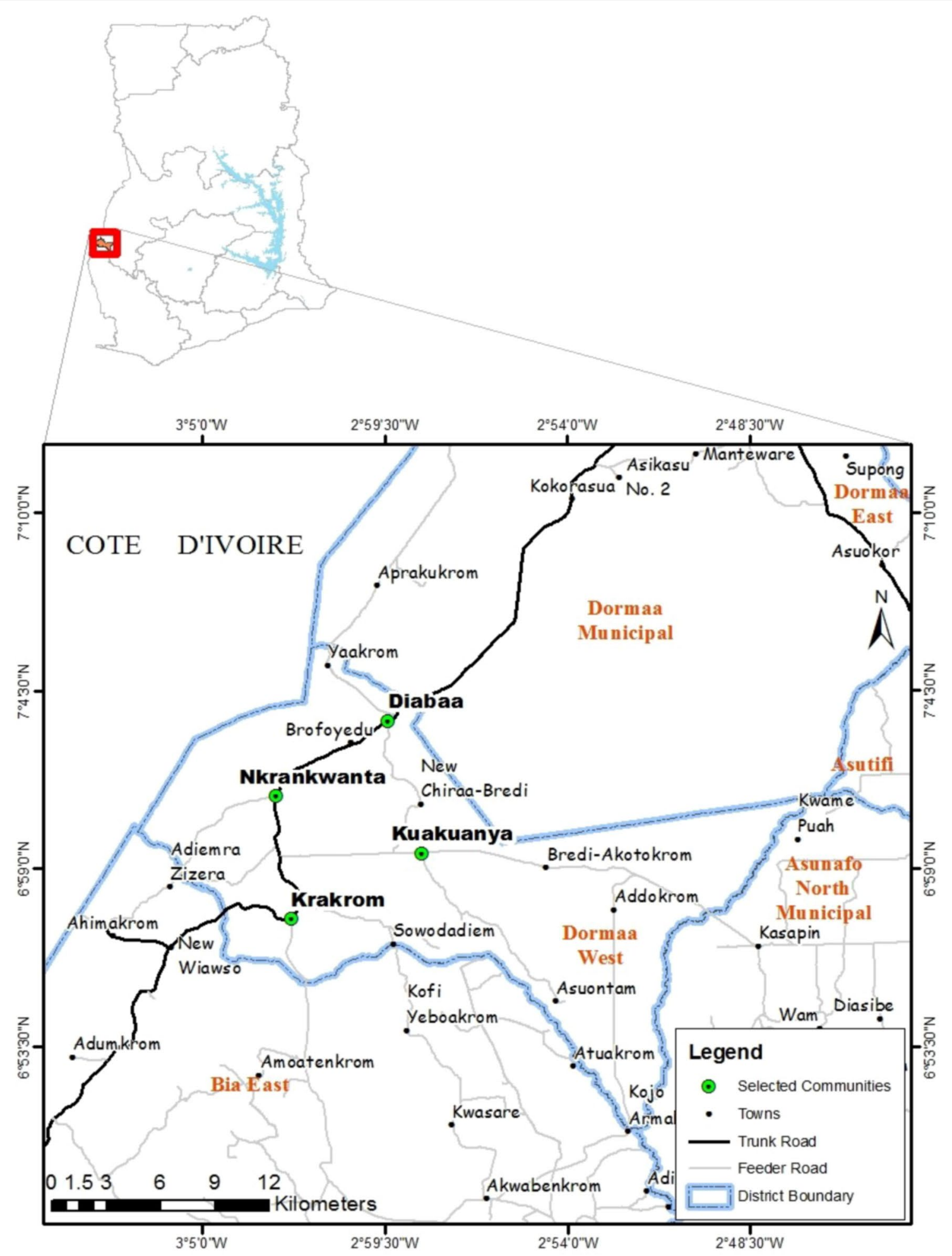

Fig. 1 Map of Dormaa West District showing selected communities 
the study. The survey covered demographic characteristics of farmers, pesticides use practices, use of PPE, and operational habits exhibited by cocoa farmers during and after pesticides applications. All participants agreed to participate in the research study by signing informed consent forms.

\section{Data analysis}

The statistical package for social sciences (SPSS) software version 20.0 was used to determine mean responses. The logit model was used to examine the factors influencing cocoa farmers' decision to use or put on PPE. The logit model was employed due to the nature of the decision variable; whether farmers wear protective equipment during spraying or otherwise. For such a dichotomous outcome $(1=$ Yes and $0=$ No) the logit model is the most appropriate analysis tool. The logistic distribution (logit) has advantage over the others in the analysis of dichotomous outcome variable in that it is extremely flexible and easily used from a mathematical point of view with a meaningful interpretation (Greene 2008). The multinomial logit (MNL) regression model was used to determine the factors that influence cocoa farmers' methods of disposing pesticides containers. The MNL model was run taking "disposal at the refuse dump" as a base category against other groups to be compared. In order to see the probability of a particular choice of disposal for a unit change in the independent variables, the regression coefficients and their significance levels were used. Also, the binary logit model was used in analysing the determinants of the operational habits exhibited by cocoa farmers during and after pesticides application. The binary logit model has been used by Mabe et al. (2014) to analyse factors that affect the choice of climate change adaptation strategies of farmers in Northern Ghana. It was also used by Fosu-Mensah et al. (2012) to assess farmers' perception of climate change, adaptation measures employed, factors and barriers affecting the adaptation process in the Sekyedumase district of Ashanti region in Ghana. The outstanding advantage of the binary logit model is that, it allows one to analyse decisions and determine the associated probabilities for the choice of a particular operational habit. It also allows for each operational habit to be analysed separately and independently unlike the use of multinomial logit model. This is to eliminate the effects of the choice of one operational habit on the other.

\section{Results and discussion}

\section{Demographic characteristics of respondents}

Table 1 presents the demographic characteristics of respondents in the study area. It was evident from the results that males dominated in cocoa farming. The study revealed that $87.5 \%$ of respondents were males while
Table 1 Demographic characteristics of cocoa farmers in the study area

\begin{tabular}{lll}
\hline Variable & Description & Percentage (\%) \\
\hline Sex of farmers & Male & 87.5 \\
Age of farmers & Female & 12.5 \\
& $20-29$ & 2.1 \\
& $30-39$ & 8.3 \\
& $40-49$ & 32.5 \\
Educational level & 50-59 & 31.3 \\
& Above 60 & 25.8 \\
& No education & 18.8 \\
Farmers years of experience & Primary/JHS & 34.6 \\
in cocoa cultivation & Middle/SHS & 43.3 \\
& Tertiary & 3.3 \\
& 5-10 & 5.8 \\
& $11-15$ & 15.7 \\
\hline
\end{tabular}

$12.5 \%$ were females. This could be attributed to the fact that males, mostly household heads, traditionally control assets such as land and tree crops than females (Anang et al. 2013). This might also be due to the labour intensive nature of cocoa farming hence less attractive to most females. The male to female ratio in this study is in line with the finding of Bosompem and Mensah (2012), Anang et al. (2013) and Boateng et al. (2014).

Majority (63.8\%) of the respondents had ages between $40-59$ years with $25.8 \%$ above 60 years. Only $10.4 \%$ of the farmers were between the ages of 20-39 years. The average age of the cocoa farmers was 52 years and the maximum age was 98 years. This generally shows that cocoa farmers in the study area are old and ageing. This has implication for cocoa production in the future as one's health normally decline with ageing. Thus there is the likelihood of decline in the production of cocoa in the study area if this trend does not change. The results of this study is in line with those reported by Bosompem and Mensah (2012), Anang et al. (2013) and Boateng et al. (2014) who indicated that most cocoa farmers (in cocoa growing districts like Birim-South, Wassa-Amenfi West and Atiwa districts of Ghana) aged 40 years and above.

Additionally, about $81.2 \%$ of the respondents had formal education, mainly middle/senior high school (43.3\%), primary/junior high school education (34.6\%) and tertiary education ( $3.3 \%$ ), with $18.8 \%$ of the farmers with no formal education. Byrness and Byrness (1978) indicated that education enhances one's ability to receive, decode and understand information. Since majority $(81.2 \%)$ of the farmers had some form of formal education, there is likelihood they will understand the 
components of pesticides usage to some extent. However, the lower level of education of the farmers may affect their ability to perform some critical tasks (e.g. calibration of sprayers, measurement and mixing of pesticides) that required a little bit of higher education. This may affect the farmers' operational habits and health related hazards in relation to chemical usage. Anang et al. (2013) and Boateng et al. (2014), reported a similar trend of education level of cocoa farmers in Ghana. However, the results of this study suggests that the literacy rate has improved over the years among cocoa farmers as Dankwa (2002) and Kumi (2003) reported 50-55 \% illiteracy rate of cocoa farmers in Ashanti and Eastern Region of Ghana. This improvement in education of cocoa farmers might be due to education policy reforms to provide education for all.

Majority $(94.2 \%)$ of the farmers had 11 or more years of farming experience in cocoa production with the rest having less than 10 years' of experience. The average number of years of cocoa farming in the study area was 21.8 years. This clearly shows that most cocoa farmers in the study area have adequate experience in cocoa production. It is therefore likely that their adoption levels of cocoa technologies such as pesticide use would be high. On the other hand, even though most of the farmers had little or no formal education, their long period of experience in cocoa production might make up for this inadequacy. The mean years of farming experience of farmers in the study area was approximately 22 years which is in line with those reported by Bosompem and Mensah (2012) and Anang et al. (2013) in the Birim-South and Wassa-Amenfi West districts of Ghana.
Years of usage of pesticides and ways of storage of pesticides by cocoa farmers

Figure 2 shows the numbers of years cocoa farmers have been using pesticides. The results show that $79.6 \%$ of cocoa farmers have been using pesticides for more than 4 years (from 5 to 16) with $20.4 \%$ using pesticides between 1-4 years. This shows how farmers depend on the use of pesticides to control pests and diseases in order to increase cocoa productivity.

On ways of storage of pesticides, farmers indicated they store pesticides on farms (43.3\%), in bedrooms used by a number of family members $(22.5 \%)$, store rooms (15.4\%), and in porch or roof top of homes (14.2\%). About $4.6 \%$ of farmers however indicated they do not store pesticides for future use, since they only buy the quantity needed at a particular time. The observation that some farmers kept pesticides within their residential homes, especially in bedrooms is worrisome. This poses high risks of pesticide exposure and health risk to farmers and their families as leakages of these chemicals can be inhaled. Farmers indicated the lack of storage facility as the reason for storage of pesticides in bedrooms. According to Kimani and Mwanthi (1995), Ngowi et al. (2001) and Murphy et al. (2002), storage of pesticides in unguarded sites in residences is common in many developing countries. The Northern Presbyterian Agricultural Services (NPAS) (2012) reported that 15 farmers in the upper East region of Ghana died in 2010 from suspected pesticides poisoning and most of these deaths was due to poor storage of pesticides. The findings in this study is in line with those reported by Ogunjimi and Farinde (2012a, b) which stated that, high percentage of cocoa farmers

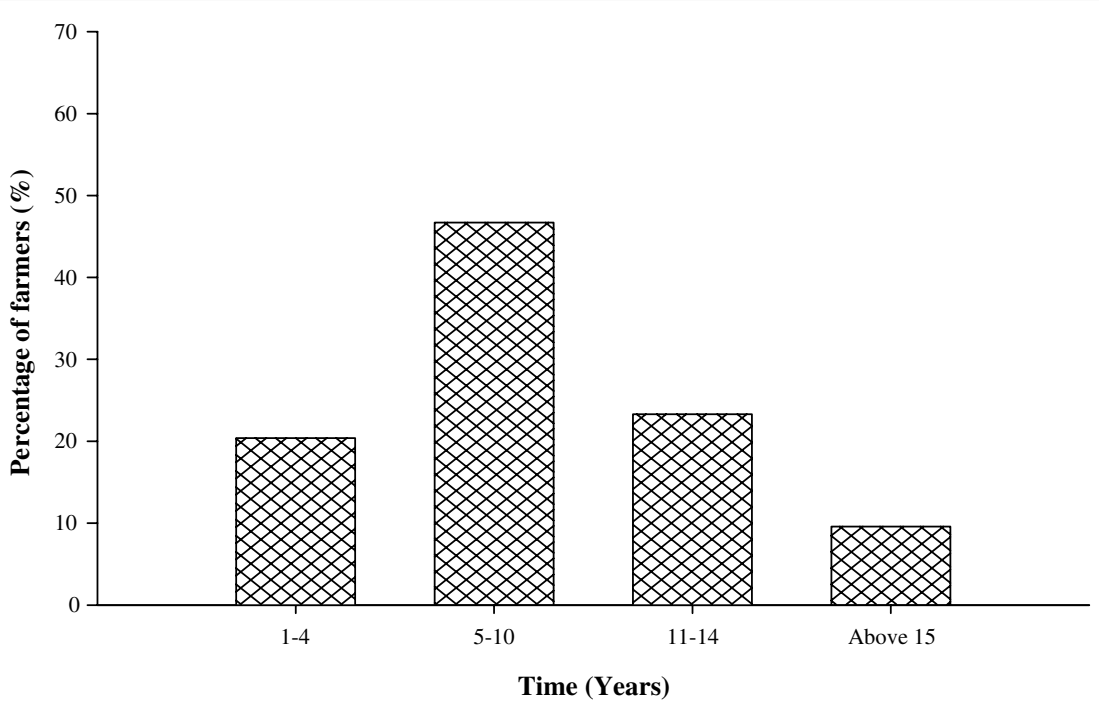

Fig. 2 Years of experience in pesticides application by cocoa farmers in Dormaa West district in Ghana 
in Osun and Edo States, Nigeria, stored pesticides in the living room together with food stuff. However, the finding of this study is contrary to the report by Tijani (2006) which stated that $87.5 \%$ of cocoa farmers in Ondo State, Nigeria, kept their pesticides in the store rooms with very few $(8.3 \%)$ storing in their bedrooms.

\section{Farmers knowledge of route of pesticide exposure and knowledge of potential impact of pesticide on environment}

Most of the respondents were aware that the eye (74.2\%), skin $(85 \%)$ and mouth $(86.3 \%)$ are the routes by which pesticides enter the human body. However, only $41.3 \%$ were aware that inhalation is also a route of exposure to pesticides. About $5 \%$ indicated lack of knowledge of any route of pesticide exposure.

On farmers' knowledge of the potential impact of pesticides used on the environment, majority $(81.7 \%)$ were aware that pesticides have the potential to cause harm to living organisms if not properly handled whereas $18.3 \%$ indicated no knowledge of potential impact of pesticides on the environment.

\section{The use of personal protective equipment (PPE) by cocoa farmers}

The failure of farmers to use PPE during pesticides application presents potential risks to pesticides exposure. Results indicated that less than half of cocoa farmers $(35 \%)$ in the study area put on full PPE (costume) during pesticide application. Twenty percent $(20 \%)$ of farmers apply pesticides with no PPE while majority of farmers (45\%) put on partial PPE during pesticides application. Wearing or putting on full PPE during pesticides application in this study was defined as wearing a cap/hat, respirator/nose mask, goggle, hand rubber glove, overall, long coat, facemask and wellington boot (rubber boot) at the time of application. However, applying pesticides with partial PPE in this study was defined as a situation where a farmer does not put on all the above listed equipment. Alternatively, applying pesticides without PPE connotes when a farmer uses his/her casual farming cloths without any of the listed PPE's. The findings in this study are in line with Sosan et al. (2008), Sosan and Akingbohungbe (2009), Ogunjimi and Farinde (2012a) and Antwi-Agyakwa (2013) which reported that only a small percentage of cocoa farmers actually wear PPE during pesticides application while majority did not see the use of PPE to be necessary. The $45 \%$ farmers who indicated the use of partial PPE used PPE items with numbers ranging from 1 to 3 . It was surprising some farmers indicated they use handkerchiefs or face towels in place of respirators/nose masks to prevent inhalation of pesticide droplets. This is not effective in protecting farmers when spraying toxic pesticides, and might increase farmers' health risk of exposure to pesticides. Not putting on full PPE during pesticides application as observed in this study might expose greater parts of farmers body to pesticides through direct contact.

Table 2 present results of percentage distribution of farmers $(80 \%)$ who wear either full or partial PPE during pesticides application. From the table, respondents indicated the use of overall (47.4\%), wellington boots (52.6\%), respirators/nose mask (35.4\%), cap/hat (29.2\%), rubber gloves (34.9\%), and goggles (28.8\%). Lawal et al. (2005) in their research on operational habits and health hazards associated with pesticides usage by cocoa farmers in Ogun State, Nigeria, made similar observations. The quality and condition of most PPE's used by farmers in the study area were poor. For instance, over $50 \%$ of the PPE's reported among 150 users were damaged or extremely contaminated when inspected. Similar observation was made by Lekei et al. (2014). The $20 \%$ farmers who do not use any PPE during pesticides application gave reasons such as high cost of PPE (33.3\%), unavailability of PPE in the market (20.8\%), discomfort in usage of PPE (20.1\%), see no need for PPE (18.8\%) and not having PPE $(7.0 \%)$ for use. Similar findings about non usage of PPE amongst farmers have been reported in studies conducted by Clark et al. (1997), Yassin (2002), Akhabuhaya (2005), Mancini et al. (2005), Damalas et al. (2006), Ntow et al. (2006) and Lekei et al. (2014). For example, Clark et al. (1997) and Ntow et al. (2006) reported that the use of PPE by Ghanaian farmers during mixing, loading and application of pesticides is poorly tolerated because of discomfort associated with the hot and humid conditions of the country, the prohibitive costs and mainly because of financial difficulties.

\section{Factors influencing famers' decision to wear personal protective equipment (PPE)}

Table 3 presents summary of the result of logit regression to estimate the factors influencing farmers' decision to put on PPE when applying pesticides. From the

\section{Table 2 Percent distribution of farmers who wear personal protective equipment}

\begin{tabular}{lc}
\hline Protective measures in use & Farm workers (\%) \\
\hline Wear rubber gloves & $67(34.9)$ \\
Wear goggles & $40(20.8)$ \\
Wear overalls & $91(47.4)$ \\
Wear wellington boots & $101(52.6)$ \\
Wear respirators/nose mask & $68(35.4)$ \\
Wear caps/hats & $56(29.2)$ \\
\hline
\end{tabular}

Multiple responses were recorded 
Table 3 Logit results on factors influencing farmers' decision to put on personal protective equipment (PPE)

\begin{tabular}{|c|c|c|c|c|c|c|}
\hline Variable & Coef. & Std. Err. & $z$ & $P$ values & $95 \%$ co & \\
\hline Gender & 0.125 & 0.776 & 0.16 & 0.872 & -1.396 & 1.645 \\
\hline Experience & $-0.306^{*}$ & 0.128 & -2.39 & 0.017 & -0.556 & -0.055 \\
\hline Age & $-0.192^{*}$ & 0.078 & -2.45 & 0.014 & -0.345 & -0.038 \\
\hline Extension service & $2.721^{* *}$ & 1.039 & 2.62 & 0.009 & 0.684 & 4.757 \\
\hline Chemical shop & $4.468^{*}$ & 2.119 & 2.11 & 0.035 & 0.314 & 8.622 \\
\hline Farm size & $0.185^{*}$ & 0.073 & 2.52 & 0.012 & 0.329 & 0.041 \\
\hline Cocoa income & 0.000 & 0.000 & 1.39 & 0.165 & -0.000 & 0.000 \\
\hline Educational level & $3.802^{* *}$ & 1.201 & 3.16 & 0.002 & 1.447 & 6.156 \\
\hline $\mathrm{FBO}$ & 0.031 & 0.995 & 0.03 & 0.975 & 1.981 & 1.919 \\
\hline Cons & $6.684^{* *}$ & 2.315 & 2.89 & 0.004 & 2.147 & 11.221 \\
\hline Log likelihood & -43.463 & & & & & \\
\hline Pseudo R2 & 0.683 & & & & & \\
\hline LR chi2 (9) & 187.30 & & & & & \\
\hline Pro $>$ chi2 & 0.0000 & & & & & \\
\hline
\end{tabular}

*,** 5 and $1 \%$ significance levels respectively

table, years of farming experience, age of farmers, access to extension service, availability of a chemical shop, farm size and educational level had an influence on decision to use PPE whereas membership of Farm Based Organization (FBO) and income from cocoa farm did not influence farmers' decision to put on protective equipment.

Access to extension service had a positively significant influence on wearing of PPE during pesticides application. This suggests that with extension services, farmers are educated on the importance of wearing PPE during pesticides application.

Farm size had a positive significant effect on decision to wear PPE during pesticides application. The result can be explained on the basis that a farmer with large farm size normally takes more time to apply pesticides; hence, it is believed that the effect of spraying without PPE may expose him/her to the harmful effect of the chemicals.

The educational level of the farmers significantly $(p<0.01)$ influenced the decision to wear protective equipment during pesticides application. The result implies that the probability of a farmer using PPE during pesticides application increases with educational level. The education of a farmer increases his/her knowledge about the harmful effects of pesticides which will motivate him/her to wear protective equipment during spraying.

However, years of farming experience had a negatively significant $(p<0.05)$ influence on wearing of protective equipment. The result implies that the probability of a farmer using PPE decreases with years of farming experience.

Similarly, age had a negatively significant $(p<0.05)$ influence on usage of PPE during pesticides application. This implies that the probability of wearing PPE during pesticide application decreases with age. The empirical result is consistent with the study's expectation which stated that there is a negative relationship between the usage of PPE during pesticide application and age of farmer. The empirical result can be explained that as farmers aged, they become used to the old ways of doing things hence, would prefer applying pesticides without PPE.

Availability of a chemical shop had significant influence on wearing of PPE when applying pesticides. This empirical result implies that the probability of wearing PPE increases with chemical shop availability. This might be due to education of farmers on the importance of wearing PPE by shop attendants.

\section{Operational habits exhibited by farmers and pesticide exposures during and after applications}

Table 4 presents some operational habits exhibited by cocoa farmers in the study area during and after

Table 4 Some operational habits exhibited by cocoa farmers during and after pesticides application

\begin{tabular}{lll}
\hline Hygiene practices & Yes (\%) & No (\%) \\
\hline Talking & 89 & 11 \\
Receiving visitors & 75.8 & 24.2 \\
Singing & 66.7 & 33.3 \\
Chewing gum or stick & 17.5 & 82.5 \\
Scooping/stirring chemicals with bare hands & 67.5 & 32.5 \\
Drinking water and alcohol & 55.8 & 44.2 \\
Whistling & 25.8 & 74.2 \\
Smoking cigarette/tobacco pipes & 20.4 & 79.6 \\
Eating food & 45 & 55 \\
Remove/blow sprayer nozzle blockages with mouth & 40.4 & 59.6 \\
Washing of personal protective equipment & 22.9 & 77.1
\end{tabular}

Multiple responses were recorded 
pesticides application. Some of the habits indicated are scooping or stirring pesticides with bare hands $(67.5 \%)$, chewing gum or stick (17.5\%), singing (66.7\%), receiving visitors (75.8\%), talking (89\%), removing/blowing/sucking blockages in sprayer nozzles with mouth $(40.4 \%)$, eating $(45 \%)$, drinking water or alcohol (55.8 \%), whistling $(25.8 \%)$ and smoking cigarette/tobacco pipes (20.4\%). These practices readily expose farmers to contamination through oral and dermal routes. Similar operational habits by farmers during pesticides application have been reported in other studies in developing countries (Lawal et al. 2005; Tijani 2006; Sosan et al. 2008; Sosan and Akingbohungbe 2009; Ogunjimi and Farinde 2012a, b).

The survey revealed that $72.1 \%$ of farmers washed their hands with soap and water after spraying operation; however, $20.8 \%$ used only water whilst $7.1 \%$ used water and other substances such as leaves of plants, sand, among others to wash their hands. The washing of hands with water and soap by farmers indicates the awareness of the harmful effects of pesticides exposure on humans. The finding of farmers washing their hands after pesticide application in this study is in line with a study by Lawal et al. (2005) on cocoa farmers in Ogun State, Nigeria, which reported that all farmers $(100 \%)$ washed their hands after pesticide application.

Even though, all farmers interviewed indicated they bath after pesticides application, the interval between spraying events and time of bathing varied among the farmers. A little above half $(52.1 \%)$ of farmers indicated they take their bath between 31-60 min after a spraying event, $24.2 \%$, between $15-30 \mathrm{~min}, 12.9 \%$ in less than $15 \mathrm{~min}$ whilst $10.8 \%$ indicated they bath at least 1 hour after spraying. The finding of more than half of farmers waiting for about 31-60 min after pesticide application before bathing is worrying, as their bodies may absorb the pesticides that come in contact with them during application and hence expose them to harmful effects of pesticides. This finding is contrary to a similar study by Ogunjimi and Farinde (2012b) which reports that majority of cocoa farmers in Osun and Edo States, Nigeria bathed immediately after spraying of chemicals. The difference in this study might be due to distance of farmers farms to source of water or homes.

Farmers who bathed few minutes after pesticides application bathed along the banks of water bodies (nearby wells and streams) within and/or around cocoa farms whilst those who took their bath between 15-60 min after pesticides application bathed in their farm house. Bathing within and/or around nearby water bodies presents another potential threat to aquatic life and humans as the pesticides could contaminate the water bodies (sources of drinking water).

The survey also revealed that $77.1 \%$ of farmers in the study area do not wash their used PPE after pesticides application, which further exposes them to health problems such as body irritation when the used PPE comes in contact with the body/skin. This finding is in line with a study by Ogunjimi and Farinde (2012a) on cocoa farmers in Osun and Edo States, Nigeria, but is contrary to a study by Tijani (2006) which reported that $68 \%$ of cocoa farmers in Ondo state, Nigeria, washed their cloths after spraying.

Investigations to know if farmers consider the direction of wind during pesticide application revealed that majority (67.5\%) of farmers do not consider the direction of wind while $32.5 \%$ answered in the affirmative. The disregards for the direction of wind during pesticides application exposes farmers to health risk of pesticides intoxication as the wind may blow the chemical towards the body, including the face of the farmer. This may also pollute the environment (soils and nearby water bodies) due to spray drift. Ntow et al. (2006) made similar observations, stating that, this poor spraying practice presents great potential to exposure of farmers to chemicals from both skin contact and inhalation. A similar observation was also made by Tijani (2006) who reported that low proportions of cocoa farmers (44\%) in Ondo State, Nigeria, followed the direction of wind when spraying.

The findings of farmers pesticides exposures through operational habits exhibited in this study confirmed the statement made by Coronado et al. (2004), that exposure to pesticide has been one of the most important occupational hazards among farmers in developing countries.

\section{Factors influencing some operational habits exhibited by cocoa farmers during and after pesticides application}

Table 5 presents the result of the binary logit model regression on factors influencing the operational habits exhibited by cocoa farmers during pesticides application.

\section{Talking}

Age and years of farming experience significantly $(p<0.05)$ and positively influenced the probability of a farmer to talk during pesticide application. It was noted that older people like to talk and share experiences, therefore, the older a farmer is, the higher the probability to talk during pesticide application. Particles of the pesticide during application can enter the mouth when talking. One would have expected that years of farming experience would have decreased the probability of a farmer talking during pesticide application. This means that farmers do not follow recommended safety measures during pesticides application.

\section{Receiving visitors}

The age of a farmer, educational level, years of farming experience and membership of farmer based organisation 


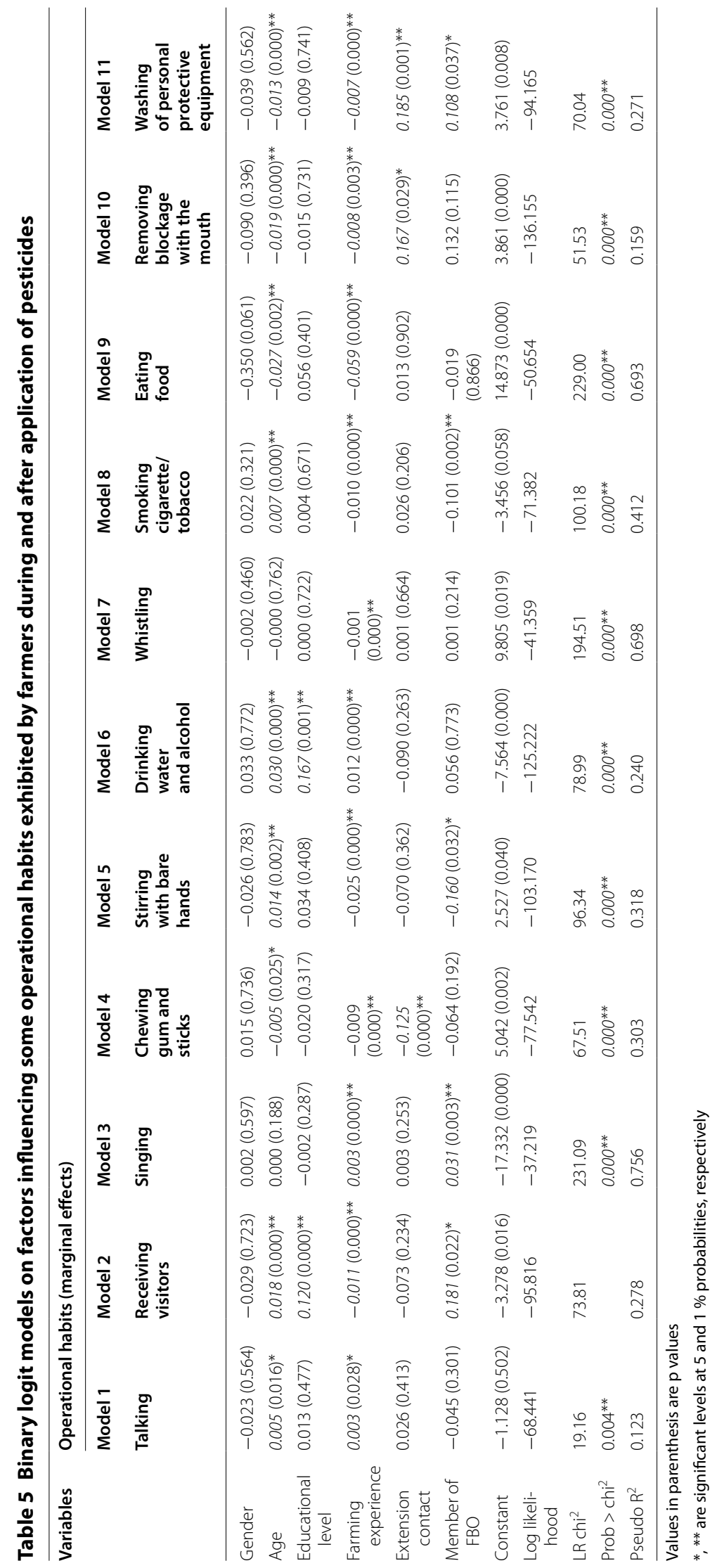


influenced the probability of a farmer to receive visitors during pesticides application.

Age and educational level had a positively significant $(p<0.01)$ influence on a farmer's likelihood to receive visitors during pesticides application. This means that as the age and educational level of a farmer increases, the probability of the farmer receiving visitors during pesticide application also increases This could be due to the fact that farmers who are younger and not educated seek information from farmers who are older and educated, therefore, the higher the probability of a farmer who is older and have gained higher level of education to receive visitors while applying pesticide.

Years of farming experience significantly $(p<0.01)$ and negatively influenced a farmer's probability of receiving visitors during pesticides application. This means that farming experience decrease the probability of a farmer to receive visitors during pesticides application. This could be due to the farmer's awareness of health implications of contact with pesticides during spraying, therefore, would not want to have visitors around during pesticides application.

The membership of FBO increased the probability $(p<0.05)$ of a farmer to receive visitors during pesticides application. This is due to the fact that farmer based organisations educate its members (farmers) on safety and good management practices including pesticides applications, therefore, other farmers may want to receive some of the information from these farmers during pesticides application time.

\section{Singing}

Years of farming experience and membership of FBO were both found to be statistically significant $(p<0.01)$ and positively influenced a farmer to sing whiles applying pesticides. This has implication on health risk as chemical particles could enter the mouth. It was expected that years of farming experience and membership of FBO by cocoa farmers should have decreased the habit of singing during pesticides application. This means that farmers do not follow recommended safety measures during pesticides application.

\section{Chewing gum or stick}

Age $(p<0.05)$, years of farming experience $(p<0.01)$ and extension service $(p<0.01)$ reduced the probability of a farmer to chew gum or stick whiles applying pesticides. Older farmers who have experience in farming may know that particles of pesticides can enter the mouth when chewing during pesticides application. Similarly, it was noted that age comes with experience; therefore, years of experience could be explained by the same reason noted for age. Extension agents educate farmers on best farming practices; hence a farmer who had access to extension services might have been educated on safety measures during pesticides application. This reduced the probability of a farmer to chew something during pesticides application. Nhemachena and Hassan (2007) reported that farming experience increases the likelihood of taking up adaptation strategies as experienced farmers have much knowledge and also information on best crop management and livestock practices to adapt.

\section{Stirring pesticides with bare hands}

Age was significant $(p<0.01)$ and positively influenced a farmer using his/her bare hands to stir chemicals during pesticide application. This could be due to the fact that older farmers are reluctant to adopt best farming practices. However, farming experience, negatively influenced $(p<0.01)$ a farmer stirring pesticides with bare hands. This might be due to farmers acquiring knowledge on the health implications of stirring chemicals with the bare hands from experience. Also, farmer based organisations might have educated farmers on best safety issues during pesticides application. Therefore, membership of FBO significantly $(p<0.05)$ and negatively influences a farmer using his bare hands to stir chemicals.

\section{Drinking water and alcohol}

Age, educational level and years of farming experience significantly $(p<0.01)$ and positively influenced habit of drinking water or alcohol during pesticides application.

Higher level of education has a link with access to information as many studies reported positive relationship between the educational level of the household head and the adoption of improved technologies (Lin 1991; Deressa et al. 2009) as well as adaptation to climate change (Maddison 2006). From this study one would have expected that age, educational level and years of farming experience would have decrease the probability of a farmer drinking water or alcohol during pesticides application. However, the result revealed otherwise.

\section{Whistling}

Years of farming experience was statistically significant $(p<0.01)$ and negatively influenced a farmer whistling during pesticides application. This means that the probability of a farmer to whistle during pesticides application decreases with increase in years of farming experience.

\section{Smoking of cigarette and tobacco pipes}

Age, years of farming experience and membership of FBO significantly $(p<0.01)$ influenced smoking of cigarette and tobacco pipes during pesticides application. This means that older farmers have a higher tendency of smoking than younger farmers. Similarly, an increase in 
years of farming experience decreased the probability of a farmer smoking. This could be due to knowledge of the impact of smoking on health risk of pesticides exposure. The membership of FBO by a farmer reduced the probability of smoking cigarette or tobacco pipe whiles applying pesticides. This could be due to education by FBO on safety measures during pesticides application.

\section{Eating}

Age and years of farming experience significantly $(p<0.01)$ and negatively influenced the probability of a farmer eating whiles applying pesticides. Thus, older farmers and farmers having many years of farming experience might have gained knowledge on safety measures during pesticides application.

\section{Removing blockages in sprayer nozzles with the mouth} Farmers age and years of farming experience significantly $(p<0.01)$ and negatively influenced removing of blockages in sprayer nozzles with the mouth. This might be due to older and experienced farmers knowing the health implications of removing blockages in sprayer nozzles with the mouth during pesticide application.

\section{Washing of personal protective equipment (PPE) after pesticides application}

The result revealed that a year increase in age $(p<0.01)$ and farming experience $(p<0.01)$ reduced the probability of a farmer washing his/her protective equipment after pesticide application whiles extension service $(p<0.01)$ and membership of FBO $(p<0.05)$ increased the probability of a farming washing his/ her protective equipment after pesticide application. The extension officers and FBOs might have educated farmers on the need to wash their protective equipment after pesticides application due to likelihood of spillage of the chemicals on the PPE during pesticides application.

\section{Observance of re-entry period after pesticides application}

Figure 3 shows the number of days' farmers wait before visiting their farms after pesticide applications. Observance of re-entry period after pesticides application is an important concept under pesticides handling to avoid contamination and to safe guard against pesticide exposure. The survey revealed that $62.5 \%$ of the farmers were not aware of post-treatment visit interval to farms with only $3.3 \%$ indicating they went to the farm few hours after application of pesticides. From the graph, $51.7 \%$ of the farmers went to their farms a day after application while 29.2 and $5.4 \%$ visited their farms after three (3) days and 1 week of pesticides application respectively. Similar observations were made by Ogunjimi and Farinde (2012a) and Antwi-Agyakwa (2013) on cocoa farmers in Nigeria and Ghana respectively. However, the findings of this study are contrary to the report by Clarke et al. (1997), which stated that about $40 \%$ of Ghanaian farmers return to work in sprayed field within a few hours of spraying, whiles $29 \%$ return a day after spraying. This trend might have changed due to farmers' awareness of possible health consequences of returning to a sprayed field immediately after application.

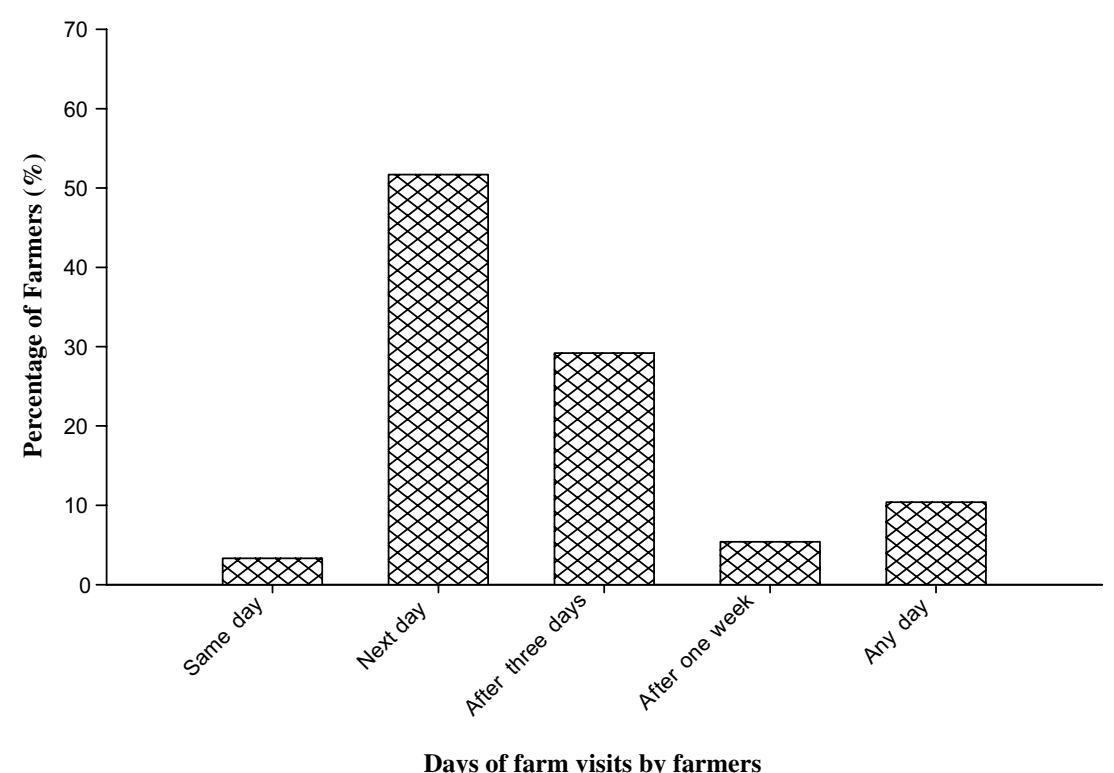

Fig. 3 Post-treatment visits of cocoa farmers in Dormaa West district in Ghana 
Disposal of chemical containers, left over spray solutions and waste water from sprayer equipment after spraying

Figure 4 presents result on how farmers in the study area disposed off empty pesticide containers after pesticides application. Majority of farmers (65\%) dump empty chemical containers on farms after application. A few others $(1.7 \%)$ dig holes in farms and bury containers, whilst $9.6 \%$ burn containers. Some farmers (10.4\%) disposed off containers at a refuse dump while $5.8 \%$ of farmers wash and re-use empty pesticide containers for other household purposes (to keep water and other food items such as salt, palm oil, among others). Disposal of left over pesticides or spraying solutions and water used for washing spraying equipment's after application varied. Fifty-five percent and Sixty-five percent of respondents dispose off left over pesticides or spray solutions and water used for cleaning sprayer after spraying on the farm, respectively, while 45 and $25 \%$ of the farmers disposed off left over spray solutions and water used for cleaning the sprayer after spraying at a designated area.

Farmers commonly disposed off empty pesticide containers, unwanted pesticides or left over spray solutions and water used for washing spraying equipment in unsafe ways. This may be an important source of pesticides exposure (Lekei et al. 2014). Similar observations were made by Tijani (2006), Ntow et al. (2006), AntwiAgyakwa (2013), Lekei et al. 2014 and Afari-Sefa et al. (2015). Empty pesticides containers were observed on cocoa farms during the field survey which confirmed what the farmers said. However, in some farms these pesticide containers were found close to water bodies. Similar observations were made by Ntow et al. (2006) and Afari-Sefa et al. (2015). According to Ntow et al. (2006), where farms are close to drinking water sources and waterways (which is the case in many farming communities in this study area) the disposal of unwanted pesticide solutions and empty containers on the field presents a pollution problem for those who drink from these water sources as well as aquatic systems which are sources of livelihood for some communities. According to Gerken et al. (2001), the improper disposal of empty pesticide containers, unwanted pesticides or left over spray solutions may lead to contamination of soil in the farm and environment by runoff, leaching or aerial distribution to other areas. Fosu-Mensah et al. (2016) reported four organophosphorus pesticide residues (chlorpyrifos, profenofos, pirimiphos-methyl and diazinon) in soil and water samples from cocoa farms in the study area which is an indication of soil and water pollution. The Environmental Health Manual (2010) identifies the community rubbish damp as the best place to discard empty pesticides containers after being wash three times with the appropriate solvent. The manual again warned against the burning of pesticides containers because they can give off poisonous gases. Unfortunately, most cocoa farmers in the study area do not follow these recommendations when handling and disposing chemical containers.

Although majority of farmers were aware of the risk of pesticides exposure, a few still used empty pesticides

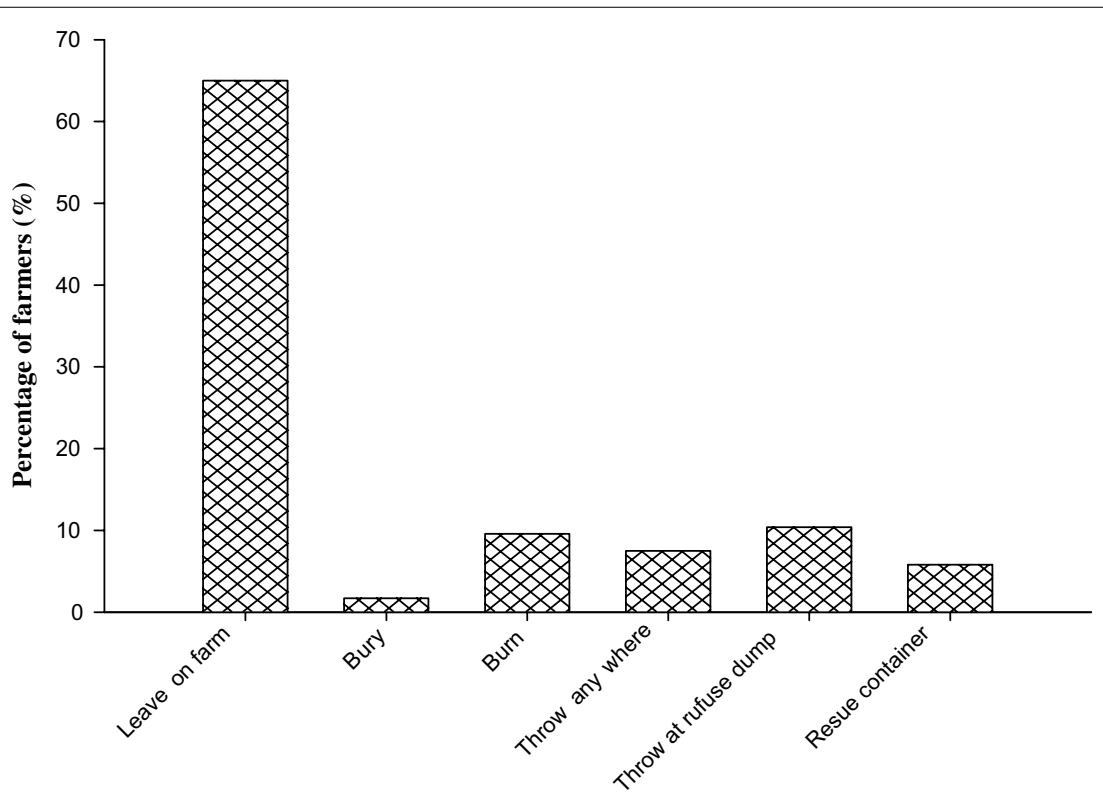

Disposal methods of pesticides containers

Fig. 4 Disposal of empty chemical containers by cocoa farmers in Dormaa West district in Ghana 
containers to keep water and other food items with the perception that once these containers are thoroughly washed with soap and water they pose no danger to their health. The re-use of pesticide containers represents a route of serious non-occupational human exposure, as several traces of pesticides could still be found in the containers even after proper washing and rinsing. A similar prevalence of re-use of pesticide containers for other household activities has been reported in other studies (Gerken et al. 2001; Heeren et al. 2003; Lawal et al. 2005; Tijani 2006; Ogunjimi and Farinde 2012b; NPAS 2012; Lekei et al. 2014; Afari-Sefa et al. 2015).

\section{Factors influencing the disposal methods of pesticide containers by cocoa farmers}

Table 6 presents the result of the multinomial logit regression on factors influencing the disposal methods of pesticide containers by cocoa farmers.

Gender and FBO significantly influenced on-farm disposal method. This implies that the probability of a male farmer leaving a pesticide container on the farm is higher than a female counterpart. FBO also had a negative relationship with on-farm disposal of pesticide containers. This implies that the probability of a farmer leaving a pesticide container on the farm decreases with membership of FBO. Gender, farming experience and age were statistically significant at 1,5 , and $5 \%$, respectively for burning as a disposal method.

Farming experience had a negative correlation with burning of pesticide containers after use. This implies that the probability of a farmer burning empty pesticide container decreases with farming experience. Similarly, the age of farmers negatively influenced the burning of pesticide containers meaning that as farmers age, they are less likely to burn empty pesticide containers on the farm.

Similarly, farming experience had a negative relationship with ground disposal of pesticide containers after use. This implies that as farmers gain more experience in farming, they are less likely to dispose off empty pesticide containers on the ground outside the farm. Similarly, there was a positive correlation between farmers age and dumping of pesticide containers on the ground outside the farm.

In addition, farming experience and age significantly influenced (at 5 and $1 \%$ respectively) farmers' choice to reuse pesticide containers. Farm experience had a negative relationship with 'reuse' of pesticide containers while the age of farmer had a positive relationship with reuse of pesticide containers.

\section{Conclusion}

This study has revealed potential opportunities for human and environmental exposure to pesticides in the Dormaa West District of Ghana. Farmers in this study had good knowledge about routes of exposure of pesticides but had poor operational and safety practices, particularly for disposal of pesticides containers, storage of pesticides and use of PPE. These can be attributed to farmers' lack of technical knowledge and inadequate training on safe pesticides use.

The study revealed that cocoa farmers were predominantly practicing habits such as eating, drinking water and alcohol, smoking cigarette and tobacco pipes, chewing gum and sticks, receiving visitors, talking, stirring chemical with bare hands, spraying against the direction

Table 6 Multinomial regression results on factors influencing the disposal methods of pesticide containers by farmers

\begin{tabular}{|c|c|c|c|c|c|c|c|c|c|c|}
\hline \multirow[t]{2}{*}{ Variable } & \multicolumn{2}{|c|}{ Leave on farm } & \multicolumn{2}{|l|}{ Burry } & \multicolumn{2}{|l|}{ Burn } & \multicolumn{2}{|c|}{$\begin{array}{l}\text { Throw on ground } \\
\text { elsewhere }\end{array}$} & \multicolumn{2}{|l|}{ Reuse } \\
\hline & Coeff. & $P>Z$ & Coef. & $P>Z$ & Coeff. & $P>Z$ & Coeff. & $P>Z$ & Coeff. & $P>Z$ \\
\hline Gender & 2.562 & $0.000^{* *}$ & -18.206 & 0.981 & 3.318 & $0.000^{* *}$ & 20.638 & 0.996 & 0.286 & 0.729 \\
\hline Education & -18.451 & 0.994 & -54.097 & 0.984 & -17.925 & 0.994 & -17.303 & 0.995 & -20.216 & 0.994 \\
\hline Experience & -0.0299 & 0.273 & 0.301 & 0.103 & -0.068 & $0.031^{*}$ & -0.099 & $0.007^{*}$ & -0.068 & $0.046^{*}$ \\
\hline Age & -0.032 & 0.097 & -0.575 & 0.115 & -0.056 & $0.024^{*}$ & 0.071 & $0.016^{*}$ & 0.082 & $0.008^{* *}$ \\
\hline Extension visit & -1.937 & 0.094 & -10.873 & 0.101 & -1.427 & 0.357 & 2.023 & 0.138 & 1.307 & 0.335 \\
\hline $\mathrm{FBO}$ & -1.540 & $0.013^{*}$ & -15.655 & 0.087 & -0.829 & 0.244 & -0.018 & 0.981 & -1.568 & 0.052 \\
\hline Cons & 19.618 & 0.994 & 34.351 & 0.989 & 17.299 & 0.995 & -10.164 & 0.998 & 12.173 & 0.996 \\
\hline Log likelihood & -194.610 & & & & & & & & & \\
\hline Pseudo $R^{2}$ & 0.3858 & & & & & & & & & \\
\hline LR chi ${ }^{2}(9)$ & 244.44 & & & & & & & & & \\
\hline Prob $>c h i^{2}$ & 0.0000 & & & & & & & & & \\
\hline
\end{tabular}

Base outcome (refuse dump)

*** 5 and $1 \%$ significance levels respectively 
of wind, removing blockages in sprayer nozzles with the mouth, among others during pesticide application. These expose farmers to potential dermal and oral contamination with pesticides.

Farmers in the study area engaged in hazardous storage of pesticides, and disposed off pesticide containers, unwanted or left over spray solutions and water used for washing sprayer on the field. This could lead to contamination of farm soils and a possible means of contamination of surrounding water bodies through leaching and runoffs. It was worrying to know that farmers re-used pesticide containers for household items such as oil and water. This might expose farmers to traces of pesticide.

The results further revealed that 35 and $45 \%$ of farmers put on full and partial PPE [including cap/hat, respirators, goggles, rubber gloves, overall and wellington boots (rubber boots)] respectively during pesticide application. However, twenty percent (20\%) of farmers applied pesticides without wearing PPE, and gave reasons of high cost of PPE, non-availability in the market, not having PPE, discomfort in usage of PPE, and no need for PPE among others. Non-usage of PPE and using partial PPE by farmers during pesticides application increases the potential of pesticide exposure, which have serious health implications. Factors that influenced the use of PPE included farming experience, age of farmer, access to extension service, availability of a chemical shop, farm size and educational level. The significant influence of extension service on the use of PPE is indicative that extension systems must be strengthened to increase farmers' knowledge and understanding of the effects of applying pesticides without PPE.

The findings are important in contributing to advocacy for training and education of cocoa farmers' on the repercussions or health hazards associated with the various operational habits they exhibit during pesticides application. Regular training of farmers on the safe use of pesticides and safe disposal of empty pesticide containers, left over spray solutions and water used to wash sprayer equipment after spraying is crucial to ensure effective management of insect pests and diseases, prevention of environmental pollution and safe pesticides usage.

\section{Abbreviations \\ PPE: personal protective equipment; WHO: World Health Organization; ILO: International Labour Organization; NPAS: Northern Presbyterian Agricultural Services; FBO: Farm Base Organization; SPSS: statistical package for social sciences.}

\section{Authors' contributions}

EDO and FMBY designed the study and wrote the protocol, EDO collected data and conducted data analysis, FMBY and EDO, drafted the manuscript, $\mathrm{MM}$ and FMBY reviewed and contributed to the writing of manuscript. All authors read and approved the final manuscript.

\section{Author details}

${ }^{1}$ Institute for Environment and Sanitation Studies (IESS), University of Ghana, P. O. Box 209, Legon, Accra, Ghana. ${ }^{2}$ Department of Architecture, Kwame Nkrumah University of Science and Technology, Kumasi, Ghana.

\section{Acknowledgements}

Authors wish to thank Mr. Derick Taylor Adu and Mr. Elisha Kwaku Denkyira for assisting in analysing some aspect of the data.

\section{Competing interests}

The authors declare that they have no competing interests.

\section{Ethics, consent and permissions}

All participants agreed to participate in the research study by signing informed consent forms.

\section{Consent for publication}

Consent to publish individual data in any form was obtained from the cocoa farmers interviewed.

Received: 10 February 2016 Accepted: 6 April 2016

Published online: 27 April 2016

\section{References}

Afari-Sefa V, Asare-Bediako E, Kenyon L, Micah JA (2015) Pesticide use practices and perceptions of vegetable farmers in the cocoa belts of the Ashanti and Western Regions of Ghana. Adv Crop Sci Tech 3:174. doi:10.4172/2329-8863.1000174

Akhabuhaya J (2005) Needs for pesticide safety outreach programmes in developing countries: a Tanzania example. Afr Newslett Occup Health and Safety 15:68-70

Anang BT, Mensah F, Asamoah A (2013) Farmers'assessment of the government spraying program in Ghana. J Econ Sustain Dev 4(7):92-99

Antwi-Agyakwa AK (2013) Susceptibility of field populations of cocoa mirids, sahlbergella singularis haglund and distantiella theobroma (distant) to bifenthrin. (Unpublished Master's thesis). Kwame Nkrumah University of Science and Technology, Kumasi, Ghana

Ayenor GK, Huis AV, Obeng-Ofori D, Padi B, Röling NG (2007) Facilitating the use of alternative capsid control methods towards sustainable production of organic cocoa in Ghana. Int J Trop Insect Sci 27(02):85-94. doi:10.1017/S1742758407780840

Boateng DO, Nana F, Codjoe Y, Ofori J (2014) Impact of illegal small scale mining (Galamsey) on cocoa production in Atiwa district of Ghana. Int J Adv Agric Res 2:89-99

Bosompem M, Mensah E (2012) Occupational hazards among cocoa farmers in the Birim south district in the eastern region of Ghana. ARPN J Agric Biol Sci 7(12):1055-1061

Byrness FC, Byrness KJ (1978) Agricultural extension and education in developing countries. Rural Dev a Chang World. p. 54-67

Clarke EEK, Levy LS, Spurgeon A, Calvert IA (1997) The problems associated pesticide use by irrigation workers in Ghana. Occup Med (Chic III) 47(5):301-308. doi:10.1093/occmed/47.5.301

Cocco P, Satta G, Dubois S, Pilleri M, Zucca M, Mannetje AM, Becker N, Benavente Y, De Sanjose S, Foretova L, Staines A, Maynadie M, Nieters A, Brennan P, Miligi L, Ennas MG, Boffetta P (2013) Lymphoma risk and occupational exposure to pesticides: results of the Epilymph study. Occup Environ Med 70:91-98. doi:10.1136/oemed-2011-100382.110

Coronado GD, Thompson B, Strong L, Griffith WC, Islas I (2004) Agricultural task and exposure to organophosphate pesticides among farm workers. Environ Heal 18:142-147

Damalas CA, Georgiou EB, Theodorou MG (2006) Pesticide use and safety practices among Greek tobacco farmers: a survey. Int J Environ Health Res 16(5):339-348

Dankwa JB (2002) Factors affecting the adoption levels of cocoa technologies in the Ashanti Region of Ghana. (Unpublished master's thesis). University of Cape Coast, Cape Coast, Ghana 
Deressa TT, Hassan RM, Ringler C, Alemu T, Yesuf M (2009) Determinants of farmers' choice of adaptation methods to climate change in the Nile Basin of Ethiopia. Glob Environ Change 19:248-255

Environmental Health Manual (2010) Disposal of unused pesticides and empty pesticide container. Available online at http://www.health.gov.au/ internet/publications/publishing.nsf/content/ohp-enhealth-manual-atsicnt-i-ch5. Accessed 20 July 2015

Fosu-Mensah BY, Okoffo ED, Darko G, Gordon C (2016) Organophosphorus pesticide residues in soils and drinking water sources from cocoa producing areas in Ghana. Environ Systems res 5(10). doi: 10.1186/ s40068-016-0063-4

Gerken A, Suglo J, Braun M (2001) Pesticides use and policies in Ghana. An economic and institutional analysis of current practice and factors influencing pesticide use. A publication of the pesticide policy project. Publication Series, Hanover University, Hanover

Ghana Statistical Service (2014) 2010 population and housing census: district analytical report of Dormaa West

Gill HK, Garg H (2014) Pesticides: environmental impacts and management strategies. In: Dr. Sonia Soloneski (ed) Pesticides-toxic aspects. InTech, Rijeka. p 188-230. doi: org/10.5772/57399

Green GL, Camilli G, Elmore PB (2006) Handbook of complementary methods in education research. Lawrence Erlbaum Associates, New Jersey

Greene WH (2008) Econometrics analysis, 6th edn. Pearson Prentice Hall, Upper Saddle River

Heeren G, Tyler J, Mandeya A (2003) Agricultural chemical exposures and birth defects in the Eastern Cape Province, South Africa. A case-control study. Environ Health Global Access Sci Source 2(1):11

International Labour Organization (ILO) (1991) Safety and health in the use of agrochemicals: a guide. ILO, Geneva

Kimani VN, Mwanthi AM (1995) Agrochemical exposure and health implications in Githunguri location—Kenya. East Afr Med J 72(8):531-535

Kumi JA (2003) Factors affecting attitudes of cocoa farmers towards replanting of cocoa in the Kwaebibirem District of the Eastern Region. Ghana. (Unpublished doctoral thesis). University of Cape Coast. Cape Coast, Ghana

Lawal BO, Torimiro DO, Banjo AD, Joda AO (2005) Operational habits and health hazards associated with pesticide usage by cocoa farmers in Nigeria : lessons for extension work. J Hum Ecol 17(3):191-195

Lekei EE, Ngowi AV, London L (2014) Farmers'knowledge, practices and injuries associated with pesticide exposure in rural farming villages in Tanzania. BMC Public Health 14:389. doi:10.1186/1471-2458-14-389

Lin J (1991) Education and innovation adoption in agriculture: evidence from hybrid rice in China. Am J Agric Econ 73(3):713-723

Mabe FN, Sienso G, Donkoh S (2014) Determinants of choice of climate change adaptation strategies in northern Ghana. Res Appl Econ 6(4):75-94

Maddison, D (2006) The perception and adaptation to climate change in Africa. CEEPA discussion paper no. 10. Centre for environmental economics and policy in Africa, University of Pretoria, South Africa

Mancini F, Van Bruggen AHC, Jiggins JLS, Ambatipudi AC, Murphy H (2005) Acute pesticide poisoning among female and male cotton growers in India. Int J Occup Environ Health 11:221-232

Mesnage R, Clair E, de Vendômois JS, Seralini GE (2010) Two cases of birth defects overlapping Stratton-Parker syndrome after multiple pesticide exposure. Occup Environ Med 67(5):359. doi:10.1136/oem.2009.052969

Murphy HH, Hoan NP, Matteson P, Abubakar AL (2002) Farmers' self-surveillance of pesticide poisoning: a 12-month pilot in northern Vietnam. Int J Occup Environ Health 8(3):201-211
Ngowi AV, Maeda D, Wesseling C, Partanen TJ, Sanga MP, Mbise G (2001) Pesticide handling practices in agriculture in Tanzania: observational data from 27 coffee and cotton farms. Int J Occup Environ Health 7:326-332

Nhemachena C, Hassan R (2007) Micro-level analysis of farmers' adaptation to climate change in Southern Africa. IFPRI Discussion Paper No. 00714. International Food Policy Research Institute, Washington D.C

Northern Presbyterian Agricultural Services (NPAS). (2012) Ghana's pesticide crisis: the need for further government action

Ntiamoah A, Afrane G (2008) Environmental impacts of cocoa production and processing in Ghana: life cycle assessment approach. J Clean Prod 16(16):1735-1740. doi:10.1016/j.jclepro.2007.11.004

Ntow WJ, Gijzen HJ, Kelderman P, Drechsel P (2006) Farmer perceptions and pesticide use practices in vegetable production in Ghana. Pest Manag Sci 62(4):356-365. doi:10.1002/ps.1178

Ogunjimi SI, Farinde AJ (2012a) Farmers'knowledge level of precautionary measures in agro-chemicals usage on cocoa production in Osun and Edo States, Nigeria. Int J Agric For 2(4):186-194. doi:10.5923/j.jijaf.20120204.10

Ogunjimi SI, Farinde AJ (2012b) Farmers'knowledge level of precautionary measures and associated health problems in the use of agro-chemicals on cocoa production in Osun and Edo states, Nigeria. Int J Agric Sci Res 2(2):1-17

PAN International (2007) A position on synthetic pesticide elimination: a pan international position paper- working group 1. Pesticide Action Network International. Retrieved from http://www.pan-international.org/panint/ files/WG1EliminatingtheWorstPesticide.pdf

Pan-Germany (2012) Pesticide and health hazards. Facts and figures. www. pan-germany.org/download/Nergift_EN-201112-web.pdf. Accessed 14 Dec 2015

Panneerselvam R (2004) Research methodology. Prentice-Hall of India Private Limited, New Delhi

Sosan MB, Akingbohungbe AE (2009) Occupational insecticide exposure and perception of safety measures among cacao farmers in Southwestern Nigeria. Arch Environ Occup Heal 64(3):185-193

Sosan MB, Akingbohungbe AE, Ojo IAO, Durosinmi MA (2008) Insecticide residues in the blood serum and domestic water source of cacao farmers in Southwestern Nigeria. Chemosphere 72(5):781-784. doi:10.1016/j. chemosphere.2008.03.015

Tanner CM, Kamel F, Ross GW, Hoppin JA, Goldman SM, Korell M, Marras C, Bhudhikanok GS, Meike K, Chade AR, Comyns K, Richards MB, Meng C, Priestly B, Fernandez HH, Langston W (2011) Rotenone, paraquat, and parkinson's disease. Environ Health Perspect 119:866-872. doi:10.1289/ ehp.1002839

Tijani AA (2006) Pesticide use practices and safety issues: the case of cocoa Farmers in Ondo State, Nigeria. J Hum Ecol 19(3):183-190

World Health Organization (WHO) (2009) World Health Organization, regional office for South-East Asia. Health implications from monocrotophos use: a review of the evidence in India. New Delhi. Retrieved from http://203.90.70.117/PDS_DOCS/B4293.pdf

Yassin MM, Abu MTA, Safi JM (2002) Knowledge, attitude, practice, and toxicity symptoms associated with pesticide use among farm workers in the Gaza Strip. Occup Environ Med 59:387-393

\section{Submit your manuscript to a SpringerOpen ${ }^{\circ}$ journal and benefit from:}

- Convenient online submission

- Rigorous peer review

- Immediate publication on acceptance

- Open access: articles freely available online

- High visibility within the field

- Retaining the copyright to your article

Submit your next manuscript at $\boldsymbol{\nabla}$ springeropen.com 